\title{
Aplicaciones del sistema CRISPR-Cas9 a la modificación genética en animales domésticos
}

\author{
Nicole Martínez-García ${ }^{1.1}$, Sergio Melero Royo ${ }^{1.2}$, Margarita M. Marqués ${ }^{2,3}$, \\ Yolanda Bayón ${ }^{2}$
}

1. Graduados en Biotecnología (promoción 2015-2019). Facultad de CC. Biológicas y Ambientales. Universidad de León. 1.1. nmarto5@estudiantes.unileon.es; 1.2.smeleroo@estudiantes.unileon.es

2. Dpto. de Producción Animal, Facultad de Veterinaria, Universidad de León.

3. Instituto de Desarrollo Ganadero y Sanidad Animal (INDEGSAL), Campus de Vegazana s/n, 24071 León.

\begin{abstract}
Resumen
Los editores genéticos, especialmente el sistema CRISPR-Cas9, han supuesto un gran avance para la modificación genética de animales. En el presente artículo, se realiza una revisión de la metodología específica en animales domésticos y sus aplicaciones en Producción Animal y Biomedicina. La parte general sobre la edición genética y el sistema CRISPR-Cas9, ha sido desarrollada en el artículo anterior centrado en las plantas. A pesar de su reciente implementación en la década actual, esta herramienta ha demostrado ya su eficacia en aspectos tan diversos como la resistencia a enfermedades, la mejora de productos de origen animal, o también el uso de animales como biorreactores, modelos de enfermedades humanas o fuente de órganos para xenotrasplante. A pesar de aspectos técnicos que aún deben ser abordados, el sistema CRISPR-Cas9 con su elevada eficiencia y diseño rápido, sencillo y económico, destaca entre las técnicas de modificación genética. Esto lo convierte, en este contexto, en la metodología con mejores perspectivas futuras, no solo para el mundo animal sino también en el ámbito de la salud humana.
\end{abstract}

Palabras clave: CRISPR, Edición genética, Producción Animal, Biomedicina.

\section{Relevancia de la edición genética}

La modificación genética de los animales de granja para mejorar la salud y el bienestar de los animales y optimizar la producción de alimentos, así como su utilización en Biomedicina ha sido un objetivo durante décadas. Aunque ya se habían logrado resultados relevantes, ha sido el desarrollo de la edición genética y, en concreto del sistema CRISPR-Cas9, lo que ha permitido incrementar la eficiencia para realizar cambios muy precisos en el genoma y ampliar el ámbito de las aplicaciones posibles (Tait-Burkard et al., 2018). En el contexto de la Biomedicina, en comparación con los roedores de laboratorio, los animales domésticos pueden llegar a ser mejores modelos preclínicos y clínicos para el estudio de

Forma de mencionar este artículo: Martínez-García, N., Melero, S., Marqués, M.M., Bayón, Y. 2019, Aplicaciones del sistema CRISPR-Cas9 a la modificación genética en animales domésticos. AmbioCiencias, 17, 32-45. ISBN: 1998-3021 (edición digital), 2147-8942 (edición impresa). Depósito legal: LE-903-07. 
muchas enfermedades humanas. Además, tienen el potencial de proporcionar productos de alto interés, desde proteínas recombinantes hasta órganos para xenotrasplante. Por otro lado, la edición genética en el ganado también puede contribuir a mejorar la Producción y Sanidad Animal. Se puede incrementar la cantidad y/o calidad de los productos de origen animal, así como conferir resistencia a enfermedades, favoreciendo la adaptación al medio ambiente. Por lo tanto, esta tecnología se ha convertido en una herramienta esencial para la modificación genética en animales. Finalmente, la edición genética permite realizar estudios de genómica funcional ya que, al inactivar genes de función desconocida, esta se puede identificar observando el fenotipo de los animales editados genéticamente.

\section{Metodología CRISPR-Cas9 en animales domésticos}

Como se ha indicado anteriormente, la parte general sobre edición genética y CRISPR-Cas9, así como sus aplicaciones en plantas, han sido desarrolladas en el artículo anterior publicado en este mismo volumen. El sistema CRISPRCas9 ha demostrado también una elevada eficacia en células animales en cultivo por lo que, en la actualidad, es el método de elección para la transgénesis en animales de granja en combinación con la técnica de transferencia nuclear de células somáticas (SCNT). Esta técnica consiste en la reconstrucción de un embrión mediante la transferencia, a ovocitos enucleados, de células somáticas que sirven como donadoras del núcleo. Estas células pueden haber sido transfectadas con los elementos del sistema CRISPR-Cas9 y, posteriormente, analizadas para se-

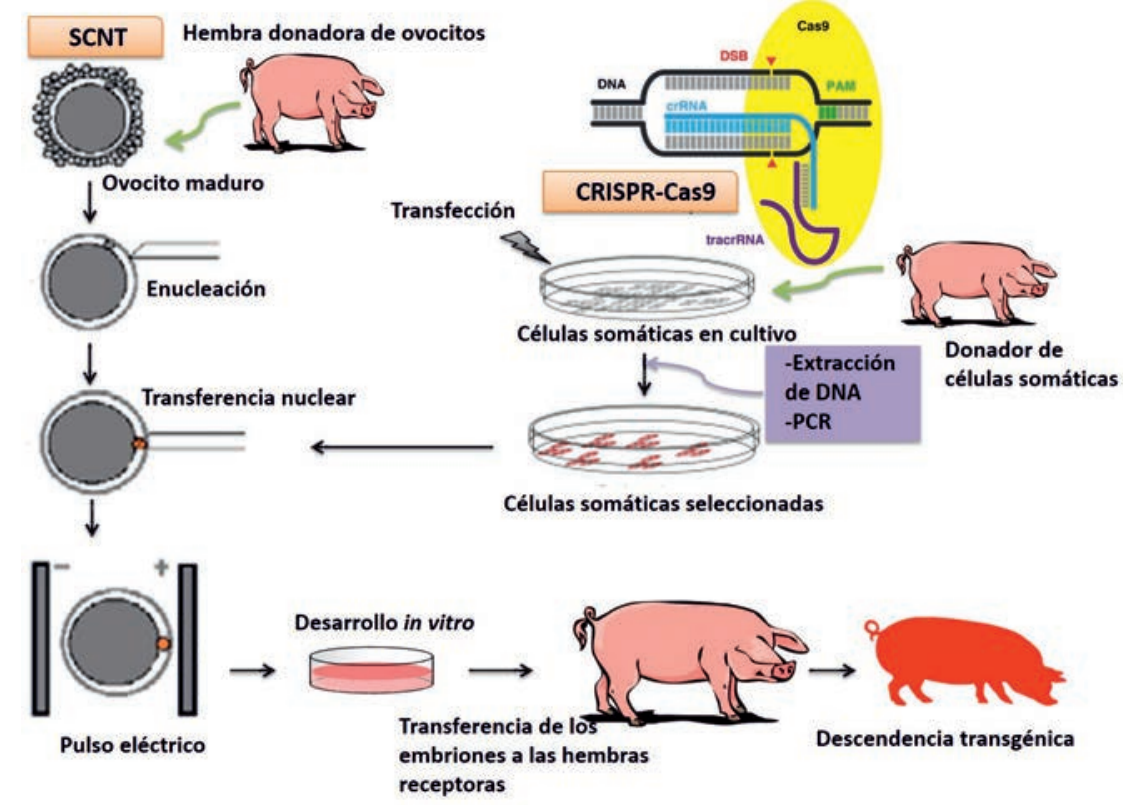

Figura 1. Etapas para la edición genética en animales domésticos mediante CRISPR-Cas9. 
leccionar las editadas correctamente (Whitelaw et al., 2015). Los embriones resultantes son transferidos a una hembra receptora en estado de pseudogestación y, tras la gestación, se obtendrán crías con la misma modificación genética que la célula somática que se utilizó como "donante"(Fig. 1).

También se ha conseguido simplificar la obtención de los animales transgénicos realizando la modificación directa de cigotos mediante microinyección (Fig. 2A), o incluso, sometiendo a una mezcla de cigotos y el sistema CRISPRCas9 a un pulso eléctrico (electroporación) (Fig. 2B).
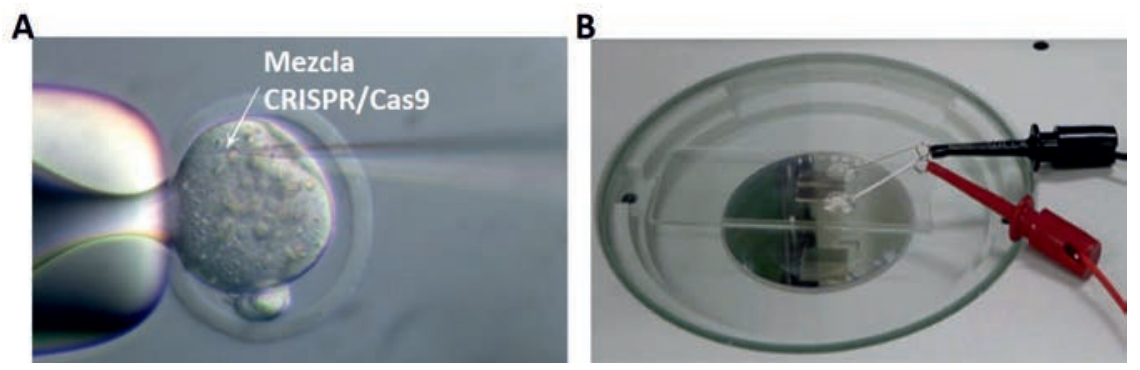

Figura 2. A) Microinyección (Doe et al., 2018). B) Electroporación (Hashimoto y Takemoto 2015).

A continuación, se revisan las investigaciones que se han llevado a cabo en animales domésticos diferenciando, por un lado, el campo de la Producción Animaly, por otra parte, la Biomedicina.

\section{Aplicaciones del sistema CRISPR-Cas9 en Producción Animal}

El sistema CRISPR-Cas9 ha demostrado su eficiencia en diversas aplicaciones en el ámbito general de la Producción Animal (Fig. 3).

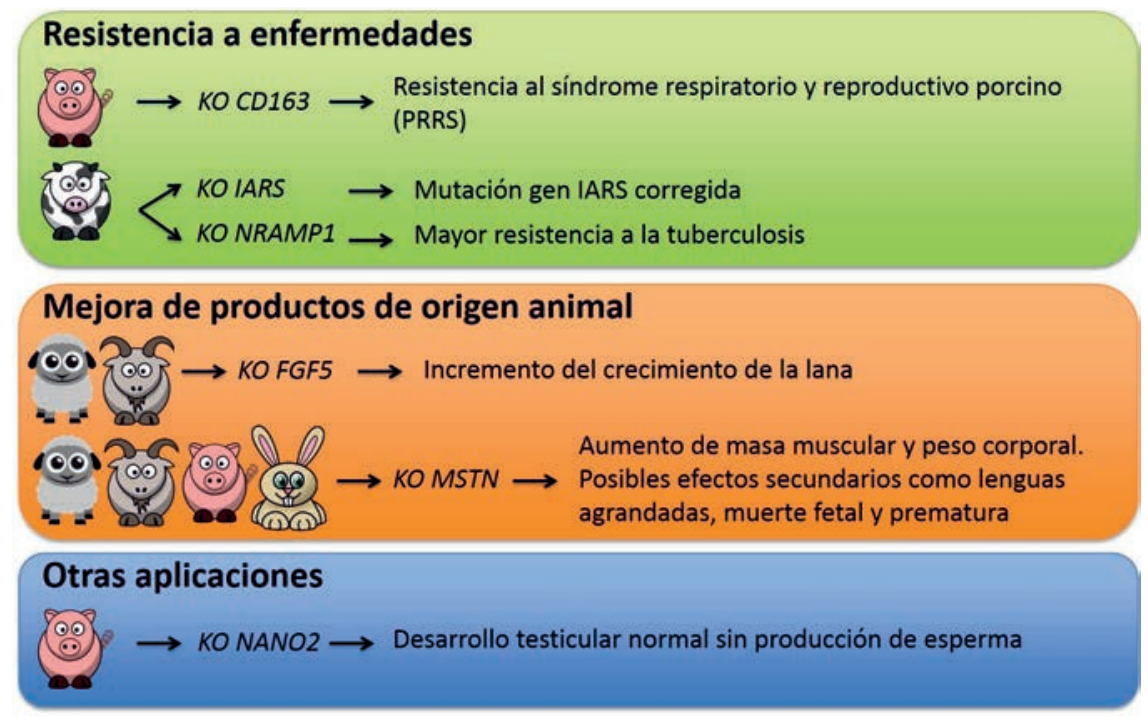

Figura 3. Aplicaciones en Producción Animal del sistema CRISPR-Cas9 en animales domésticos. Se indica si se ha llevado a cabo la inserción (KI o knockin) o inactivación (KO o knockout) de un determinado gen y los resultados observados. 
Resistencia a enfermedades

Incrementar la resistencia tanto a enfermedades genéticas como infecciosas supone mejorar la productividad de las explotaciones así como la calidad de vida de los animales y, en ciertos casos, reducir la probabilidad de transmisión de enfermedades al ser humano. En este contexto es de destacar, por ser una de las investigaciones recientes más relevante, la generación de cerdos resistentes al síndrome respiratorio y reproductivo porcino (PRRS), una enfermedad altamente contagiosa de distribución mundial. Los efectos más devastadores se observan en lechones jóvenes y cerdas gestantes (abortos) y es una de las enfermedades que produce mayores pérdidas económicas a los productores de ganado por-ino (Whitworth y Prather, 2017). El agente causal de la enfermedad es el virus del PRRS (PRRSV), con dos tipos genéticamente diferentes: PRRSV-1 y PRRSV-2, predominantes en Europa y América, respectivamente.

Basándose en el hecho ya conocido de que el dominio 5 del receptor CD163 es esencial para la unión del virus, Burkard et al. $(2017,2018)$ generaron, mediante CRISPR-Cas9, cerdos knockout para dicho dominio. Este es uno de los dominios ricos en cisteína (SRCR) de la región extracelular del receptor CD163. Para ello microinyectaron en el citoplasma de cigotos una combinación del RNAm de Cas9 y dos sgRNA que flanqueaban al exón 7 codificante del dominio 5 , provocando la eliminación del exón. La transferencia de los blastocistos a cerdas receptoras generó parte de los lechones con la deleción del exón 7. Finalmente, mediante cruzamientos se obtuvieron lechones heterocigotos y homocigotos ( $\triangle$ SRCR5) (Fig. 4A).

Los ensayos in vitro demostraron resistencia de las células $\triangle \mathrm{SRCR} 5$ a la infección por PRRSV-1 y PRRSV-2. Por su parte, los ensayos in vivo de desafío con PRRSV-1, permitieron comprobar la resistencia de los animales $\triangle$ SRCR5 a la infección. Así, tras la administración intranasal del virus, se observaron signos clínicos de la enfermedad exclusivamente en los lechones wildtype (WT). Además, una prueba ELISA detectó la presencia de anticuerpos contra el virus en lechones $W T$ pero no en $\triangle \mathrm{SRCR}_{5}$ (Fig. 4B). Igualmente, la necropsia evidenció lesiones en pulmones de los animales $W T$ mientras que no se observaron en los $\Delta$ SRCR5 (Fig. 4C). Un aspecto a destacar es que, en todos los casos, se mantenían las funciones biológicas de la proteína CD163. La generación de estos animales ofrece una gran oportunidad para la industria porcina, permitiendo una mejora tanto en la productividad de las explotaciones como en el bienestar animal.

Además de este ejemplo, también se han obtenido vacas con mayor resistencia a la tuberculosis, una zoonosis de elevado coste económico en el ganado 
bovino asociado a la eliminación de animales en la granja y restricciones de movimientos pecuarios. En los animales editados genéticamente, se redujo la multiplicación de la bacteria causante de la enfermedad, Mycobacterium bovis, insertando copias adicionales de genes endógenos asociados con la inmunidad innata, como el gen NRAMP1 (Fig. 5A) (Gao et al., 2017). También se ha logrado corregir enfermedades genéticas tales como el síndrome de isoleucil-tRNA sintetasa (IARS), frecuente en el ganado bovino negro japonés, causado por la sustitución de un solo nucleótido. La reparación se ha conseguido incorporando la secuencia correcta mediante el sistema CRISPR-Cas9 (Ikeda et al., 2017).
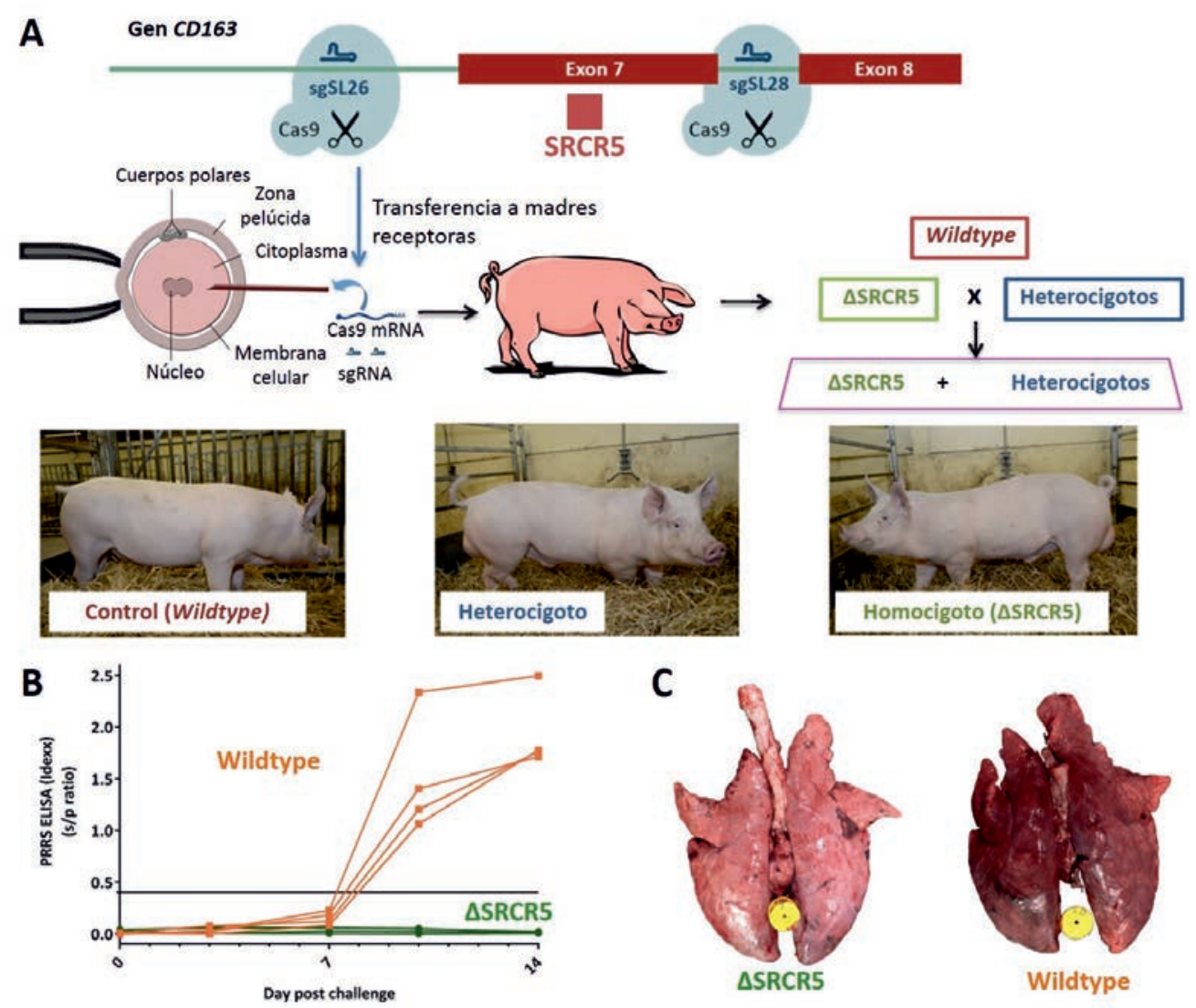

Figura 4. A) Proceso de edición genética para la generación de cerdos $\triangle$ SRCR5. B) Detección de anticuerpos frente a PRRSV-1 y C) Necropsia pulmonar en lechones WT y $\Delta$ SRCR5. Burkard et al. $(2017,2018)$.

\section{Mejora de productos de origen animal}

En este grupo de aplicaciones, el gen más estudiado es MSTN, codificante de la proteína miostatina, que interviene en el control del crecimiento muscular en los mamíferos. Se conocen mutaciones naturales en algunas especies animales que inactivan la proteína o reducen su expresión causando un aumento de la musculatura, como se ha encontrado en algunos casos en el ganado bovino y ovi- 
no e incluso en el ser humano. El fenotipo resultante se conoce como doublemuscling o hipertrofia muscular. Sobre esta base y utilizando el sistema CRISPR-Cas9 se han generado animales $K O$ para este gen en diversas especies (Fig. 3) tales como cabras, conejos, ovejas y cerdos (Tanihara et al., 2016; Zhang et al., 2019) (Fig. 5B). Se han conseguido así diferentes niveles de incremento de la masa muscular y peso corporal aunque, en alguna ocasión, se han encontrado efectos secundarios negativos.

Otro de los productos de origen animal cuyas características se ha intentado mejorar es la lana. Uno de sus rasgos de calidad es la longitud, que está controlada por el factor de crecimiento fibroblástico 5 (FGF5), inhibidor dominante de la duración del ciclo capilar. Se ha observado el fenotipo de pelo largo de forma natural en algunas especies como perros y gatos debido a una mutación en el gen FGF5. En base a esto, con el objetivo de aumentar la longitud de la lana, se ha utilizado el sistema CRISPR-Cas9 para generar tanto ovejas como cabras KO FGF5, obteniéndose un incremento del crecimiento de la lana y del número de folículos pilosos (Fig. 5C).

A

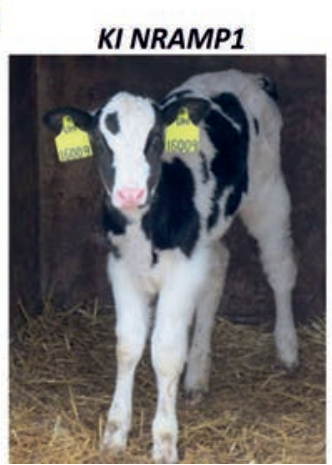

B

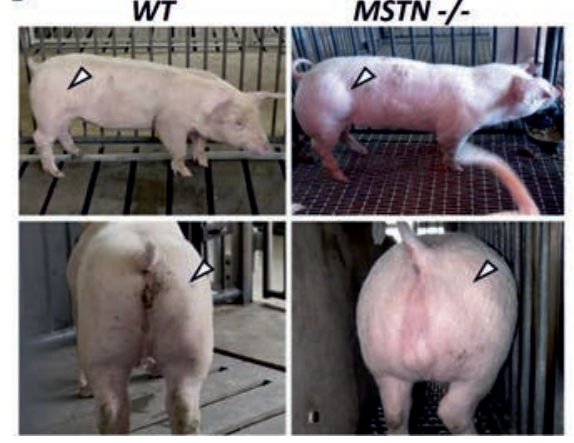

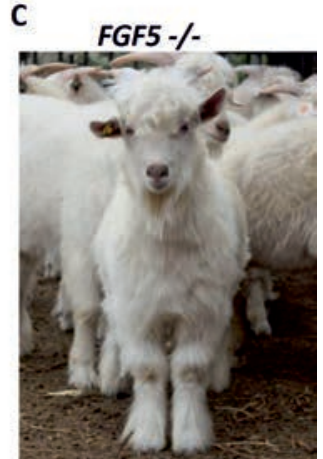

Figura 5. A) Vacas con mayor resistencia a la tuberculosis (Gao et al., 2017). B) Masa muscular aumentada en cerdos KO en comparación con $W T$ (Tanihara et al., 2016). C) Cabras con incremento de la longitud de la lana (Wang et al., 2016a).

\section{Otras aplicaciones}

Los métodos de mejora genética tradicional, mediante selección y cruzamiento implican resultados a largo plazo y un alto coste. Una de las posibles aplicaciones más singulares de la utilización del sistema CRISPR-Cas9, es la generación de animales estériles que pueden utilizarse como receptores para el trasplante de espermatogonias de sementales genéticamente deseables (Lin et al., 2019). En este sentido, ya se han logrado los primeros resultados mediante la inactivación de genes importantes para el desarrollo de células germinales, como el caso de cerdos $K O$ para el gen $\mathrm{NANO}_{2}$ (Park et al., 2017), que presentan el fenotipo de ablación de la línea germinal masculina en individuos homocigotos, 
pero con otros aspectos del desarrollo testicular normales. Estos animales se usarían para distribuir germoplasma en la población.

\section{Aplicaciones del sistema CRISPR-Cas9 en Biomedicina}

Mediante este sistema se han conseguido avances en la obtención de animales modificados genéticamente para diferentes aplicaciones Biomédicas (Fig. 6).

\section{Modelos de enfermedad}

La disponibilidad de animales modelo de una enfermedad humana constituye una herramienta muy valiosa para investigar el proceso patológico y desarrollar tratamientos adecuados. En muchos casos, en los que no se dispone de un modelo natural, la modificación genética hace posible generar dichos modelos. Aunque depende del tipo de enfermedad, el cerdo es el animal considerado frecuentemente como más idóneo dada su similitud con la especie humana en aspectos como el tamaño de sus órganos y su fisiología. Mediante el sistema CRISPR-Cas9 se han conseguido ya cerdos modelo para distintas enfermedades y síndromes humanos (Fig. 6), como por ejemplo la enfermedad de NiemmanPick de tipo C, caracterizada por la mutación en el gen NPC1L1, o los síndromes de Waardenburg y Tietza causados por mutaciones en el gen MITF y que provocan hipopigmentación y sordera (Zhou et al., 2016).

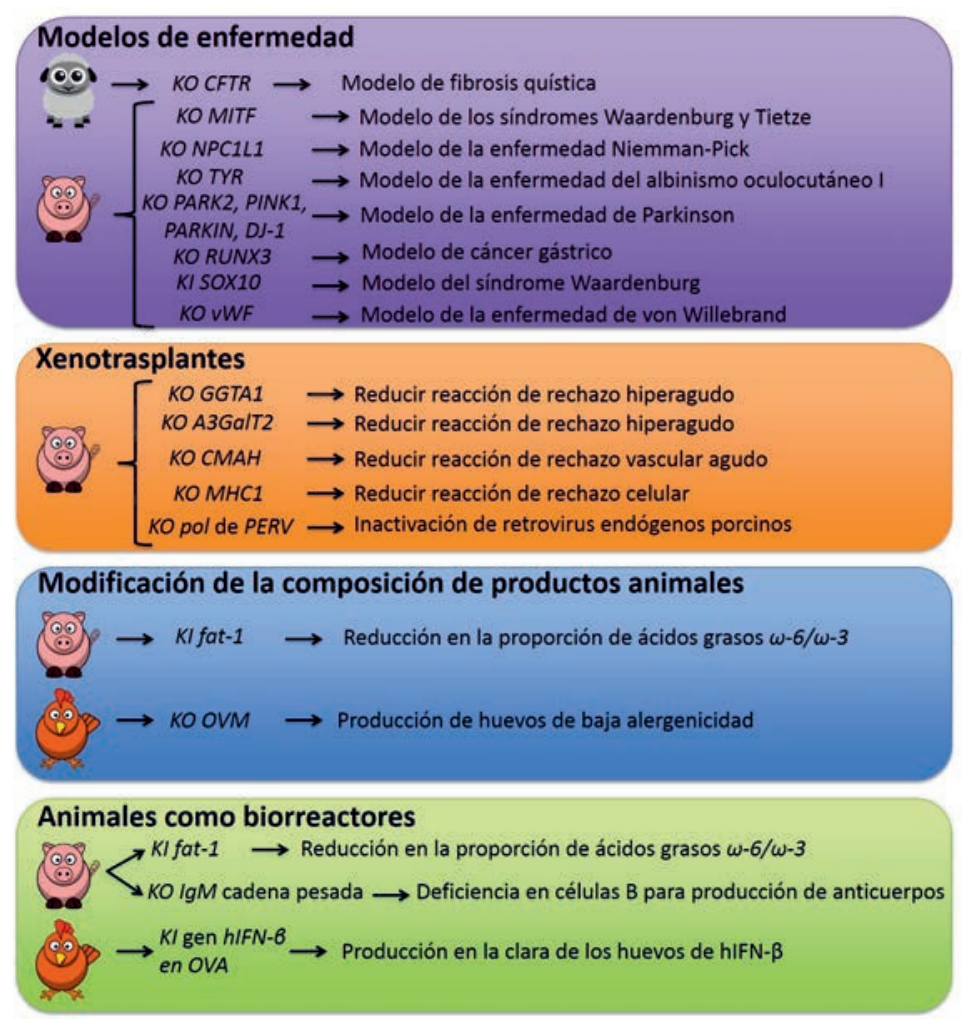

Figura 6. Aplicaciones en Biomedicina del sistema CRISPR-Cas9 en animales domésticos. Se indica si se ha llevado a cabo la inserción $(K I)$ o inactivación $(K O)$ de un determinado gen y los resultados observados. 
También se han generado cerdos modelo para el albinismo oculocutáneo tipo 1, la enfermedad de Parkinson o la enfermedad de Von Willebrand. El albinismo oculocutáneo tipo 1 está causado por mutaciones en el gen $T Y R$, que codifica la proteína tirosinasa responsable de la producción de melanina. Al obtener cerdos KO TYR (Zhou et al., 2014), se observó que habían perdido el pigmento de la piel, cabello y ojos (Fig. 7A), al igual que ocurre en humanos. En la enfermedad de Parkinson se han identificado mutaciones en más de 10 genes, entre ellos PARK2, PINK1, DJ-1 y parkin. En este caso, se han generado cerdos doble y triple $K O$ y se está investigando su utilidad como modelos de la enfermedad (Wang et al., 2016b). La enfermedad de Von Willebrand está causada por el déficit del gen $v W F$. En este caso, para obtener el modelo en cerdos se dirigió el sgRNA al exón 5 del gen, observándose que los $K O$ obtenidos padecían de hemorragia severa como ocurre en humanos.

Otra de las patologías que ha concentrado un gran número de investigaciones es la fibrosis quística, una enfermedad genética grave que cursa, entre otros síntomas, con alteraciones pulmonares progresivas que provocan la muerte. Está causada por la mutación en el gen CFTR que codifica una proteína encargada de regular el transporte activo de iones de cloro hacia el exterior de la membrana, y cuya alteración causa el acúmulo de una sustancia mucosa en los diferentes conductos del organismo. Aunque se habían obtenido cerdos modelo de esta enfermedad antes del desarrollo de la edición genética, mediante el sistema CRISPR-Cas9 se han generado recientemente ovejas KO (Fan et al., 2018) que, debido a su similitud en la anatomía y desarrollo pulmonar con la especie humana, desarrollaron una enfermedad similar a la patología en humanos (Fig. 7B).

A

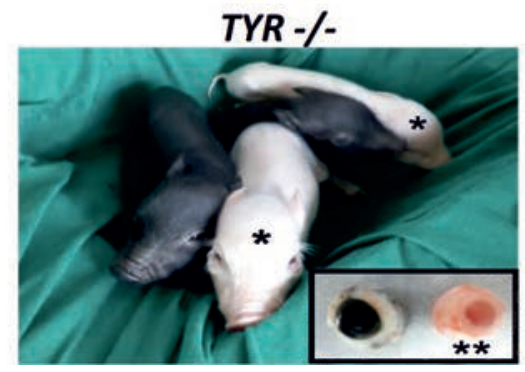

B

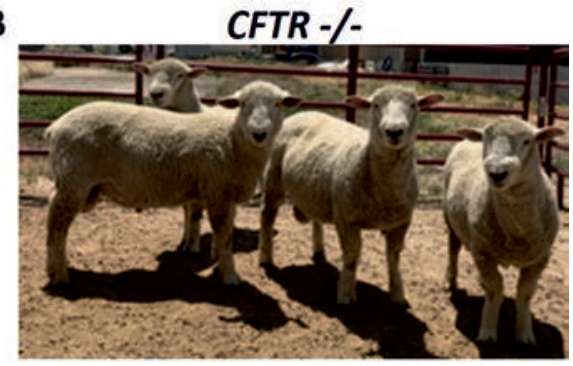

Figura 7. A) Pelaje* y ojos** de cerdos modelo del albinismo oculocutáneo tipo 1 (Zhou et al., 2014). B) Ovejas modelo de fibrosis quística (Fan et al., 2018).

\section{$\underline{\text { Xenotrasplantes }}$}

La dramática escasez de órganos humanos para trasplante hace necesarias otras alternativas, entre ellas la utilización de tejidos y órganos de otras especies en las que se haya reducido la posible reacción de rechazo inmunológico 
mediante modificación genética. Al igual que ocurre con los animales modelos de enfermedad, el cerdo es considerado la mejor opción, por sus semejanzas con los humanos y su escasa probabilidad de transmisión de patógenos en comparación con los primates. Con este fin, se han llevado a cabo numerosas investigaciones, muchas de ellas previas a la utilización de la edición genética. Mediante el sistema CRISPR-Cas9 se han generado ya cerdos $K O$ para los genes GGTA1 y A3GalT2 ambos inactivos en humanos (Butler et al., 2016). Estos genes codifican el epítopo $\alpha$-gal, responsable del rechazo hiperagudo que es la reacción fisiológica inicial y más destructiva en un trasplante. También se ha inactivado el gen $C M A H$ que determina el antígeno Neu5Gc y B4GalNT2 que codifica un glicano, ambos responsables del rechazo vascular agudo. Además, se han originado cerdos $K O$ para el gen $M H C 1$ encargado de la activación de los linfocitos Ty las células Natural-Killer, responsables del rechazo celular.

Otra de las preocupaciones en el área de los xenotrasplantes, es la posibilidad, aunque remota, de activación y transmisión de retrovirus endógenos porcinos (PERV). En este sentido, ha resultado crucial la investigación de Niu et al. (2017) quienes lograron, mediante CRISPR-Cas9, inactivar la totalidad de los PERV de un genoma porcino, utilizando dos sgRNA dirigidas al gen pol que codifica la transcriptasa inversa del virus.

Modificación de la composición de productos animales

En este caso, el objetivo es obtener productos de mayor calidad y más saludables para el hombre. En la gallina, la edición genética ha permitido modificar genes alergénicos de la clara de huevo, como la ovoalbúmina (OVA) y el ovomucoide (OVM), lo que reduce la respuesta inmunitaria de los individuos sensibles a artículos que contienen clara de huevo. En el estudio de Oishi et al. (2016), mediante microinyección del sistema CRISPR-Cas9 en los embriones, obtuvieron gallinas $K O$ que producían huevos de menor alergenicidad. En el cerdo, con el objetivo de aumentar la calidad de la carne se ha usado el sistema CRISPR-Cas9 para incrementar su contenido en ácidos grasos omega $3(\omega-3)$, de conocidas propiedades cardioprotectoras y anticancerígenas. Se consiguió mediante la inserción del gen fat-1 del nematodo Caenorhabditis elegans en el intrón 1 del locus ROSA26 del genoma de cerdo. El gen fat-1 codifica la enzima desaturasa n-3, de la que carecen la mayoría de mamíferos, y que permite transformar los ácidos grasos $\omega-6$ en $\omega-3$, reduciendo así la relación $\omega-6 / \omega-3$ (Fig. 8A)(Li et al., 2018). 


\section{Animales como biorreactores}

Se pueden obtener proteínas recombinantes de interés terapéutico a partir de animales modificados genéticamente (individuos KI). Por ejemplo, debido a la escasez de suministro de sangre humana y los riesgos asociados a la transmisión de enfermedades, se ha buscado la producción alternativa de albúmina sérica humana (HSA) en animales. La HSA es la proteína plasmática más abundante, desempeña funciones homeostáticas importantes en la fisiología humana y se utiliza como tratamiento para el fallo hepático y shock traumático. Mediante el sistema CRISPR-Cas9 se ha insertado el gen $A L B$ humano en el exón 1 del locus $A L B$ de cerdo. De esta manera se expresa la HSA al mismo tiempo que se bloquea la expresión endógena de la albúmina de cerdo, facilitando la purificación de la proteína humana (Peng et al., 2015). También se ha conseguido producir interferón- $\beta$ humano (hIFN- $\beta$ ) en la clara de huevo de gallina. Esta proteína se utiliza para el tratamiento de enfermedades como la hepatitis $\mathrm{C}$ o la esclerosis múltiple. Para ello, Oishi et al. (2018) insertaron, mediante el sistema CRISPR-Cas9, el gen $h I F N-\beta$ en el locus $O V A$ obteniendo gallinas transgénicas que producían una elevada concentración de hIFN- $\beta$ biológicamente activo en la clara de los huevos. En estos, la porción de la clara más cercana a la yema era blanquecina y turbia, demostrándose que era la zona de mayor depósito de la proteína recombinante (Fig. 8B). Por último, indicar que se han obtenido anticuerpos humanos a partir de cerdos que carecen de células B endógenas, evitando así que se produzca el reconocimiento de los anticuerpos y se destruyan. Se ha conseguido en cerdos mediante la inactivación de la secuencia de la cadena pesada de la IgM necesaria para la supervivencia de las células B durante el desarrollo temprano (Chen et al., 2015).

A

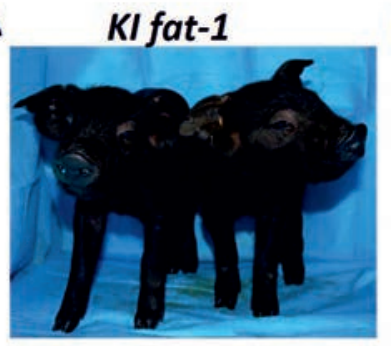

B

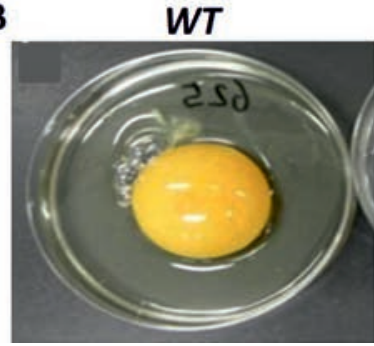

KI hIFN-6

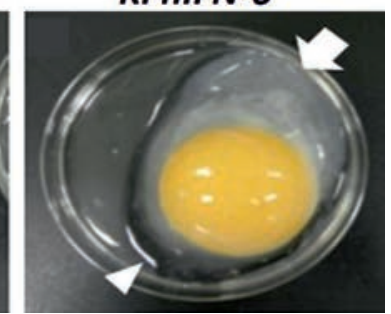

Figura 8. A) Cerdos con el gen fat-1 insertado (Li et al., 2018). B) Huevos de gallinas $W T$ y KI. Se señala con una flecha la zona de mayor depósito de la proteína recombinante (Oishi et al., 2018).

\section{Consideraciones finales}

En relación con las posibilidades de utilización en la práctica de los animales editados genéticamente y, si nos centramos en el momento actual, esta difiere según la aplicación. Los modelos animales de enfermedad se están aplican- 
do en Biomedicina, y se realizan ya ensayos clínicos de xenotrasplantes en primates y, previsiblemente, en humanos en un futuro próximo. De igual modo, puesto que ya están autorizadas algunas proteínas recombinantes humanas purificadas a partir de la leche (antitrombina III e inhibidor de la esterasa C1) o huevos (lipasa ácida lisosómica) de animales transgénicos convencionales, se espera que otras obtenidas mediante edición genética, como el interferón- $\beta$ humano descrito anteriormente, sean aprobadas por las agencias reguladoras correspondientes. Sin embargo, los productos de origen animal destinados al consumo están sometidos a una normativa mucho más estricta. De hecho, en la actualidad, solamente hay un producto animal, el salmón transgénico, cuya comercialización está permitida en países como Estados Unidos y Canadá. A pesar de que los expertos han concluido que los productos de animales editados genéticamente no representan un riesgo mayor para el consumidor (revisado por Lamas-Toranzo et al., 2017), su comercialización en EEUU precisa una evaluación reglamentaria obligatoria y, en la Unión Europea cuya política es más restrictiva en estos temas, esta prohibida al ser considerados OMGs. Esta situación es un reflejo de la reacción negativa del público hacia la transgénesis animal, por lo que mejorar la percepción pública hacia la modificación genética es esencial para la aplicación del sistema CRISPR-Cas9. Por otro lado, el bienestar animal es una preocupación asociada a cualquier experimentación animal, regulada por normativas específicas orientadas al principio de las $3 \mathrm{R}$ (reemplazar los animales por otras opciones cuando sea posible, reducir su número al mínimo necesario y refinar los procedimientos). En este sentido, es interesante destacar que, en comparación con las tecnologías anteriores, CRISPR reduce el número de animales requeridos para generar la modificación. Las distintas aplicaciones también pueden influir en la opinión de los consumidores, ya que es más probable que estos acepten modificaciones destinadas a mejorar, por ejemplo, la resistencia a las enfermedades que las dirigidas a caracteres productivos de los animales (Van Eenennaam et al., 2019).

Se puede concluir que la aparición de los editores genéticos, especialmente el sistema CRISPR-Cas9, ha permitido generar animales modificados genéticamente de forma más sencilla y eficiente. A pesar de su reciente implantación en animales domésticos, ha conseguido ya resultados relevantes en los ámbitos de la Biomedicina y la Producción Animal, aunque es necesaria una regulación adecuada basada en criterios científicos. Finalmente, indicar que la aceptación social precisa de una mayor información a los ciudadanos sobre la edición genética. 


\section{Bibliografía}

Burkard, C., Lillico, S. G., Reid, E., Jackson, B., Mileham, A. J., Ait-Ali, T., Whitelaw, C. B. A. y Archibald, A. L. 2017. Precision engineering for PRRSV resistance in pigs: macrophages from genome edited pigs lacking CD163 SRCR 5 domain are fully resistant to both PRRSV genotypes while maintaining biological function. PLOS Pathogens 13:1-28

Burkard, C., Opriessnig, T., Mileham, A. J., Stadejek, T., Ait-Ali, T., Lillico, S. G., Whitelaw, C. B. A. y Archibald, A. L. 2018. Pigs lacking the scavenger receptor cysteine-rich domain 5 of $\mathrm{CD} 163$ are resistant to porcine reproductive and respiratory syndrome virus 1 infection. Journal of Virology 92:1-13

Butler, J. R., Skill, N. J., Priestman, D. L., Platt, F. M., Li, P., Estrada, J. L., Martens, G. R., Ladowski, J. M., Tector, M. y Tector, A. J. 2016. Silencing the porcine iGb3s gene does not affect Gal ${ }_{3} \mathrm{Gal}$ levels or measures of anticipated pig-to-human and pig-to-primate acute rejection. Xenotransplantation 23:106-116

Chen, F., Wang, Y., Yuan, Y., Zhang, W., Ren, Z., Jin, Y., Liu, X., Xiong, Q., Chen, Q., Zhang, M., et al. 2015. Generation of B cell-deficient pigs by highly efficient CRISPR/Cas9-mediated gene targeting. Journal of Genetics and Genomics 42:437-444

Doe, B., Brown, E. y Boroviak, K. 2018. Generating CRISPR/Cas9-Derived Mutant Mice by Zygote Cytoplasmic Injection Using an Automatic Microinjector. Methods and protocols 1:1-12

Fan, Z., Perisse, I. V., Cotton, C. U., Regousky, M., Meng, Q., Domb, C., van Wettere, A. J., Wang, Z., Harris, A., White, K. L. y Polejaeva, I. A. 2018. A sheep model of cystic fibrosis generated by CRISPR/Cas9 disruption of the CFTR gene. JCI Insight 3:1-12

Gao, Y., Wu, H., Wang, Y., Liu, X., Chen, L., Li, Q., Cui, C., Liu, X., Zhang, J. y Zhang, Y. 2017. Single Cas9 nickase induced generation of NRAMP1 knockin cattle with reduced off-target effects. Genome Biology 18:1-15

Hashimoto, M. y Takemoto, T. 2015. Electroporation enables the e cient mRNA delivery into the mouse zygotes and facilitates CRISPR/Cas9-based genome editing. Scientific Reports 5:1-7

Ikeda, M., Matsuyama, S., Akagi, S., Ohkoshi, K., Nakamura, S., Minabe, S., Kimura, K. y Hosoe, M. 2017. Correction of a disease mutation using CRISPR/Cas9-assisted genome editing in japanese black cattle. Scientific Reports 7:1-9

Lamas-Toranzo, I., Guerrero-Sánchez, J., Miralles-Bover, H., Alegre-Cid, G., Pericuesta, E. y Bermejo-Álvarez, P. 2017. CRISPR is knocking on barn door. Reproduction in Domestic Animals 52:39-47

Li, M., Ouyang, H., Yuan, H., Li, J., Xie, Z., Wang, K., Yu, T., Liu, M., Chen, X., Tang, X., et al. 2018. Site-specific fat-1 knock-in enables significant decrease of n6PUFAs/n-3PUFAs ratio in pigs. Genes|Genomes|Genetics 8:1747-1754

Lin, H., Deng. Q. y Shi, L. (2019). Application and development of CRISPR/Cas9 technology in pig research. En Gene Editing - Technologies and Applications 
(eds. Chen, Y. C. y Che, S. J.) doi: 10.5772/intechopen.85540

Niu, D., Wei, H. J., Lin, L., George, H., Wang, T., Lee, I. H., Zhao, H. Y., Wang, Y., Kan, Y., Shrock, E., et al. 2017. Inactivation of porcine endogenous retrovirus in pigs using CRISPR-Cas9. Science 357:1303-1307

Oishi, I., Yoshii, K., Miyahara, D., Kagami, H. y Tagami, T. 2016. Targeted mutagenesis in chicken using CRISPR/Cas9 system. Scientific Reports 6:1-10

Oishi, I., Yoshii, K., Miyahara, D. y Tagami, T. 2018. Efficient production of human interferon beta in the white of eggs from ovalbumin gene-targeted hens. Scientific Reports 8:1-12

Park, K. E., Kaucher, A. V., Powell, A., Waqas, M. S., Sandmaier, S. E. S., Oatley, M. J., Park, C. H., Tibary, A., Donovan, D. M., Blomberg, L. A., et al. 2017. Generation of germline ablated male pigs by CRISPR/Cas9 editing of the NANOS2 gene. Scientific Reports 7:1-9

Peng, J., Wang, Y., Jiang, J., Zhou, X., Song, L., Wang, L., Ding, C., Qin, J., Liu, L., Wang, et al. 2015. Production of human albumin in pigs through CRISPR/Cas9mediated knockin of human cDNA into swine albumin locus in the zygotes. Scientific Reports 5:1-6

Tait-Burkard, C., Doeschl-Wilson, A., McGrew, M. J., Archibald, A. L., Sang, H. M., Houston, R. D., Whitelaw, C. B. y Watson, M. 2018. Livestock 2.0 - genome editing for fitter, healthier, and more productive farmed animals. Genome Biology 19:1-11

Tanihara, F., Takemoto, T., Kitagawa, E., Rao, S., Do, L.T.K., Onishi, A., Yamashita, Y., Kosugi, C., Suzuki, H., Sembon, S., et al. 2016. Somatic cell reprogramming-free generation of genetically modified pigs. Science Advances 2:1-8

Van Eenennaam, A. L., Wells, K. D. y Murray, J. D. 2019. Proposed U.S. regulation of gene-edited food animals is not fit for purpose. Nature Partner Journals 3:1-7

Wang, X., Cai, B., Zhou, J., Zhu, H., Niu, Y., Ma, B., Yu, H., Lei, A., Yan, H., Shen, Q., et al. Y. 2016a. Disruption of FGF5 in cashmere goats using CRISPR/Cas9 results in more secondary hair follicles and longer fibers. PLoS ONE 11:1-12

Wang, X., Cao, C., Huang, J., Yao, J., Hai, T., Zheng, Q., Wang, X., Zhang, H., Qin, G., Cheng, J., et al. 2016b. One-step generation of triple gene-targeted pigs using CRISPR/Cas9 system. Scientific Reports 6:1-7

Whitelaw, C. B. A., Sheets, T. P., Lillico, S. G. y Telugu, B. P. 2015. Engineering large animal models of human disease. Journal of Pathology 238:247-256

Whitworth, K. M. y Prather, R. S. 2017. Gene editing as applied to prevention of reproductive porcine reproductive and respiratory syndrome. Molecular Reproduction and Development 84:926-933

Zhang, Y., Wang, Y., Yulin, B., Tang, B., Wang, M., Zhang, C., Zhang, W., Jin, J., Li, T., Zhao, et al. 2019. CRISPR/Cas9-mediated sheep MSTN gene knockout and promote sSMSCs differentiation. Journal of Celullar Biochemistry 120:17941806

Zhou, X., Wang, L., Du, Y., Xie, F., Li, L., Liu, Y., Liu, C., Wang, S., Zhang, S., Huang, X., 
et al. 2016. Efficient generation of gene-modified pigs harboring precise orthologous human mutation via CRISPR/Cas9-induced homology-directed repair in zygotes. Human Mutation 37:110-118

Zhou, X., Xin, J., Fan, N., Zou, Q., Huang, J., Ouyang, Z., Zhao, Y., Zhao, B., Liu, Z., Lai, S., et al. 2014. Generation of CRISPR/Cas9-mediated gene-targeted pigs via somatic cell nuclear transfer. Cellular and Molecular Life Sciences 72:11751184 . 